\title{
Preparation of Multi-Wall Carbon
} Nanotubes/Graphene Composites with Cadmium Sulfide in Dye-Sensitized Solar Cells (DSSCs)

\author{
Entidhar Alkuam \\ Department of Physics and Astronomy, University of Arkansas, Little Rock, USA \\ Email: eaalkuam@ualr.edu
}

How to cite this paper: Alkuam, E. (2021) Preparation of Multi-Wall Carbon Nanotubes/Graphene Composites with Cadmium Sulfide in Dye-Sensitized Solar Cells (DSSCs). Advances in Materials Physics and Chemistry, 11, 111-119.

https://doi.org/10.4236/ampc.2021.116011

Received: January 1, 2021

Accepted: June 26, 2021

Published: June 29, 2021

Copyright $\odot 2021$ by author(s) and Scientific Research Publishing Inc. This work is licensed under the Creative Commons Attribution International License (CC BY 4.0).

http://creativecommons.org/licenses/by/4.0/

\begin{abstract}
In the present work, Dye Sensitized Solar Cells (DSSCs) have been fabricated by utilizing a dense layer of photoelctrode cadmium sulfide thin film (CdS) as n-type, which prepared by spray coating, while p-type electrode was multi-wall carbon nanotubes/graphene (MWNT-G) composites. The experimental results showed the higher energy conversion efficiency for CdS/MWNT-G was $0.056 \%$ in comparison with the others, which were CdS/MWNT with $0.044 \%$ and CdS/G with $0.037 \%$ respectively, which referred to improvement in the conductivity by using MWNT-G. The microstructure and nanostructure of CdS, MWNT, G, and MWNT-G nanocomposite were carried out by employing Scanning Electron Microscopy (SEM). X-Ray Diffraction (XRD) has been used to get crystal size of CdS, Raman scattering, and optical absorption also used for characterizations the samples. This study promised to increase and enhance the conversion efficiency of photovoltaic devices.
\end{abstract}

\section{Keywords}

CdS, Multi-Wall Carbon Nanotubes/Graphene, Dye-Sensitized Solar Cell

\section{Introduction}

Dye-sensitized photoelectrodes lie at the root of many recent developments used to advance processes central to photovoltaic, photocatalytic, and optoelectronic instruments [1] [2] [3]. These photoelectrodes pair a semiconductor film that has an inherently wide band gap, with a dye. As the name suggests, the dye plays a significant part in the charge transfer and light absorption characteristics of 
these photoelectrodes, the main components of DSSCs are shown in Figure 1.

Metallic sulfides [4] and chalcogenide compounds [5] have been a long-term focus for researchers who study photocatalysis, over several recent decades. Cadmium sulfide (CdS) is one semiconductor photocatalyst that has attracted continuous investigation because two of its important characteristics are optimal: the fitting location of the conduction band and valence band edge, alongside the useful band gap of the compound [4] [6] [7].

A number of techniques have been employed to produce CdS nanocrystalline thin films. Some of them are using physical methods and the others are using chemical methods. Among these are spray deposition, electrodeposition, pulsedlaser deposition [8] [9], RF sputtering [9] [10], sol-gel, hydrothermal processes solvothermal processes [11] [12] [13] [14], vacuum evaporation [15], successive ionic layer adsorption and reaction (SILAR) [16], chemical bath deposition (CBD) [17] [18] [19], chemical vapor deposition (CVD) [9] [20].

The inherently high conductivity and high charge mobility characteristics of graphitic nanoparticles have stimulated research into a wide array of possible new uses for such materials. Two of the indisputably most important new materials are carbon nanotubes and graphene. These discoveries have resulted in an upheaval in the development of electronic devices.

Recently, studies have demonstrated that the integration of composite science and technology constituents into the polymeric matrices of electronic components results in several orders of magnitude enhancement of the electrical conductivity. This is achieved without affecting other critical features, such as the mechanical and optical properties.

Two-dimensional (2-D) structured graphene continues to display significant promise for use as a conductive nanomaterial in organic solar cells and DSSCs. Graphene has emerged as a positive measure in new photoanode applications [21].

Because of their capability to transport high current and their mechanical flexibility, multi-walled carbon nanotubes (MWNTs) have demonstrated marked benefits in the role of conducting matrix in nanocomposites [22].

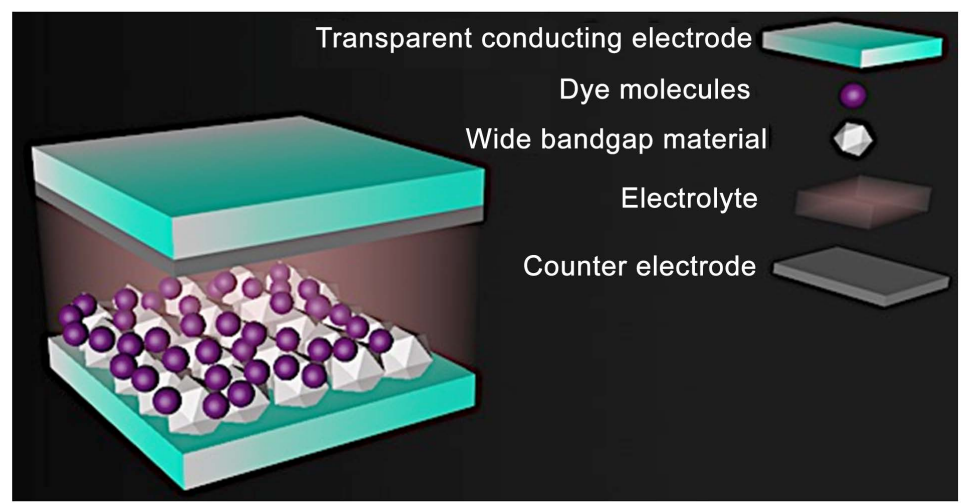

Figure 1. The main components of DSSCs. 
The main aim of this work is to fabricate low cost DSSCs based on photo electrode CdS thin film prepared by low cost and simple spray coating deposition technique on FTO. While counter electrode MWNT/G nanocomposites were synthesized on FTO by multi-step spray coating instead of using high cost electrodes like platinum $(\mathrm{Pt})$.

\section{Experiments}

\subsection{Chemicals and Materials}

Cadmium sulfide $(\mathrm{CdS})$ powder $99.995 \%$, ethylene glycol $\left(\mathrm{CH}_{2} \mathrm{OH}\right)_{2}$, multi-wall carbon nanotubes $>99 \%$, Di-tetrabutylammonium cis-bis(isothiocyanato)bis (2,2-bipyridyl-4,4-dicarboxylato)ruthenium(II) (N-719 dye) $\mathrm{C}_{58} \mathrm{H}_{86} \mathrm{~N}_{8} \mathrm{O}_{8} \mathrm{RuS}_{2} \quad 95 \%$ and graphene were purchased from Sigma Aldrich, iodine $\mathrm{I}_{2}$ was from mallinckodi chemical work. Fluorine doped tin oxide (FTO) coated glass substrate, with a resistivity of 12 - $17 \Omega \cdot \mathrm{cm}$ was purchased from Nanocs. N,N-Dimethylformamide (DMF), acetone $\left(\mathrm{C}_{3} \mathrm{H}_{6} \mathrm{O}\right)$, potassium iodide $(\mathrm{KI})$ and ethanol $\left(\mathrm{C}_{2} \mathrm{H}_{6} \mathrm{O}\right)$ were purchased from Fisher Scientific. All the chemicals were used as received without further purification.

\subsection{Preparation of CdS, Dye N719, Electrolyte and MWNT-G}

$3 \mathrm{~g}$ of CdS nanopowder was added into ethanol, and DI water with purity 18.20 $\mathrm{M} \Omega \cdot \mathrm{cm}$ (15\%: 15\%: 70\%) were mixed and produce a dispersion which stirred for $50 \mathrm{~min}$, then the solution was deposited by using spray coating technique to produce a layer of CdS onto clean FTO and the deposition occurred at $150^{\circ} \mathrm{C}$ on hot plate to evaporate the solvents. The cleaning of FTO under sonication for 5 min in each of acetone, ethanol and deionized water (DI). Annealing was carried out for CdS in the oven at $450^{\circ} \mathrm{C}$ for $30 \mathrm{~min}$ to improve the crystal size. The resultant CdS thin film was immersed in a dye bath for 10 hours, which was prepared by dissolving $0.01 \mathrm{~g}$ of the dye (N719) in $20 \mathrm{ml}$ ethanol.

The electrolyte solution was made by dissolving $0.83 \mathrm{~g}$ of potassium iodide, and $0.127 \mathrm{~g}$ from iodine, in $10 \mathrm{ml}$ ethylene glycol. $0.3 \mathrm{mg} / \mathrm{ml}$ from each of MWNT and Graphene dissolved in DMF to prepare a dispersion of each one individually and leave it on stir for $3 \mathrm{~h}$, then deposited on FTO by spray coating at $125^{\circ} \mathrm{C}$ on hot plate. The mass ratio (25:25:50) for MWNT, Graphene and DMF is (25:25:50) to prepare MWNT-G composite. The spray coating deposition carried out on hot plate $125^{\circ} \mathrm{C}$ to deposit MWNT-G nanocomposite, the main steps to produce DSSCs device are shown in Figure 2.

\subsection{Solar Cell Fabrication}

The sandwich device of the DSSCs consist of FTO/CdS as photoelectrode and FTO/MWNT-G as counter electrode while the dimensions of spacer are $2.5 \times$ $2.5 \mathrm{~cm}^{2}$ for outer area, which filled with few drops from electrolyte. The schematic diagram of FTO/CdS/MWNT-G/FTO is shown in Figure 3. 


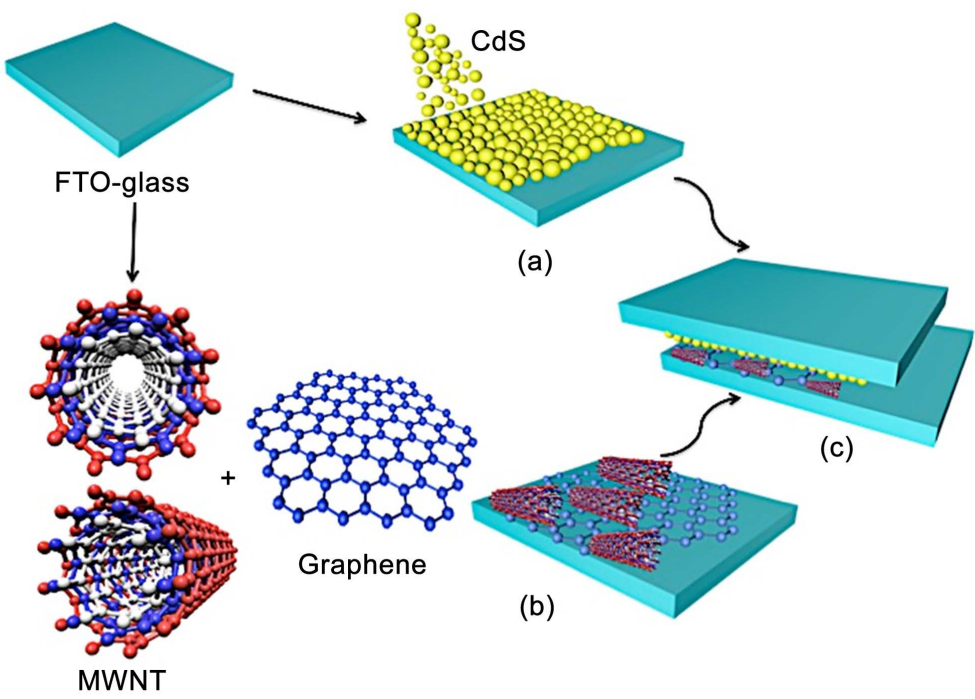

Figure 2. General procedure utilized to prepare DSSCs device. (a) Preparation of CdS/FTO, (b) Preparation of MWNT-G/FTO, (c) Make a sandwich device of DSSCs.

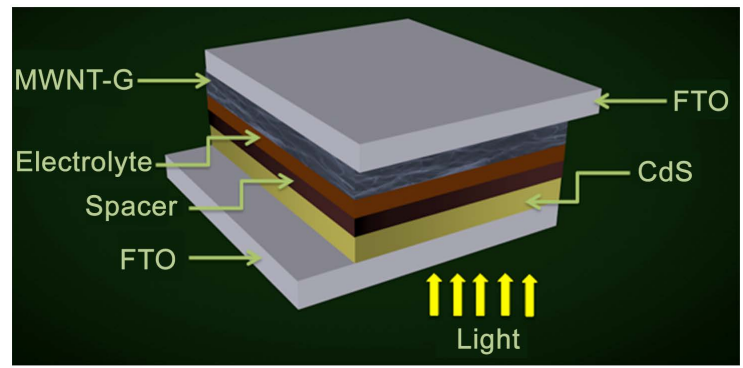

Figure 3. The schematic diagram of FTO/CdS/MWNT-G/FTO.

\section{Characterization}

Scanning Electron Microscopy (SEM, JEOL JSM7000F) was used to investigate the microstructure and nanostructure of the samples. Raman spectra were analyzed by EZRaman-N to get more information about the crystalline of the film. UV-visible spectrometer was employed to measure the optical absorbance. The crystal structure of the synthesized CdS was determined by X-ray diffractometer (XRD) patterns on a Rigaku Miniflex $600 \mathrm{X}$-ray diffractometer with copper target; the wavelength of Copper $\mathrm{K}$-alpha $\mathrm{Cu} \mathrm{K} \alpha$ radiation is $1.54056 \AA$. Keithley 2400 sourcemeter measuring was employed to record current-voltage (I-V) characteristics.

\section{Results and Discussion}

Figure 4(a) and Figure 4(b) show the typical surface SEM images of CdS nanoparticles at different locations and magnifications, it is obviously seen the aggregation of particles to produce uncracked and a rough thin film of CdS which increase its ability to adsorb the dye.

The micro and nano structure of Graphene sheets has been examined by SEM images as shown in Figure 4(c) and Figure 4(d); the images clearly indicate the low surface coverage of Graphene sheets as compared to MWNT. 

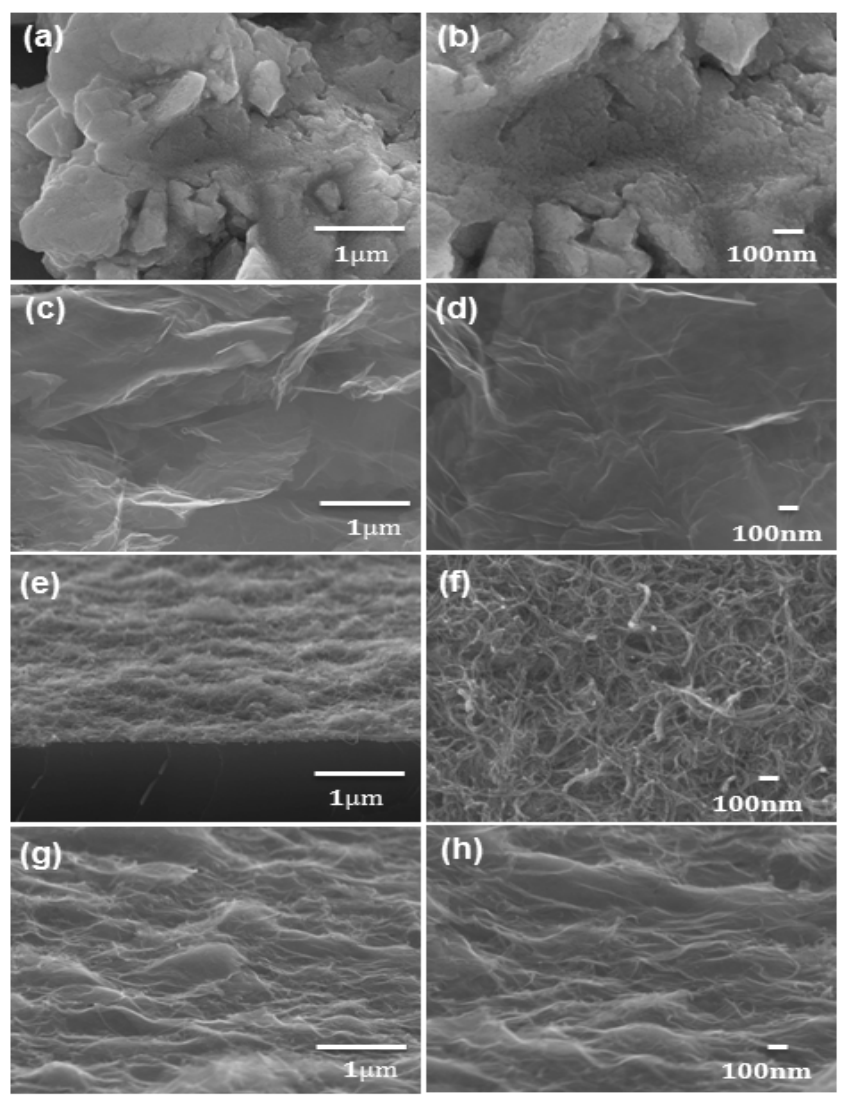

Figure 4. SEM images of; Top view of micro-graphs and nano-graph CdS synthesized on FTO (a), (b), top view of micro-graphs and nano-graphs grapheme (c), (d), nano-graph cross section and micro-graph top view of multiwall carbon nanotube (e), (f), and top view micro-graphs and nano-graph of G-MWNT nanocomposite (g), (h).

Figure 4(e) and Figure 4(f) at low and high magnifications indicate the formation of pristine MWNT uniformly covered FTO with a large surface coverage, the average diameter and length of MWNT was (5 - 25) nm and (5 - 60) $\mu \mathrm{m}$ repectively.

The morphology of the MWCNT-G nanocomposite was studied through SEM as shown in Figure 4(g) and Figure 4(h). The graphene diffuses between the MWNT film pores and produces good interference of nanocomposite.

Figure 5(a) presents the prospective XRD pattern of the CdS on glass. The six diffraction peaks are corresponding to (100), (002), (101), (110), (103) and (112) plane respectively referring that film is hexagonal CdS phase.

From Scherer formula [23] $D=0.94 \lambda / \beta \cos \theta$, where $D$ is the crystallite size, $\lambda$ the wavelength of the X-ray radiation ( $\mathrm{Cu} \mathrm{K} \alpha=0.15406 \mathrm{~nm}), \theta$ the diffraction angle and $\beta$ is the full width at half maximum (FWHM) of the peak, particle size of CdS for $\mathrm{H}$ (002) before and after annealing was calculated and it was $49 \pm 0.9$ $\mathrm{nm}$ and $71 \pm 7 \mathrm{~nm}$ before and after annealing respectively, it can be observed that the intensity and sharpness peak corresponding to the plane (002) increases after the annealing, which in terms indicate to improve the crystal size of CdS after annealing. 
Two optical vibrational Raman modes for CdS can be observed at $300 \mathrm{~cm}^{-1}$ and $600 \mathrm{~cm}^{-1}$, as shown in Figure 5(b). In nanometer sized, the strong and sharper Raman peak of CdS shifted to a wavenumber $300 \mathrm{~cm}^{-1}$ referred to fundamental longitudinal optical phonon (1LO) while the broadband peak at wavenumber $600 \mathrm{~cm}^{-1}$ indicates to the first overtone mode (2LO), it is reasonable with the reports [24].

Figure 6 shows the typical absorption spectra of FTO, CdS with and without dye. It is notable that the absorbance of the CdS with dye is higher than that of the CdS only and absorbs more photons in the region between $420-900 \mathrm{~nm}$, which shows that the incident light harvested by a dye molecules.

Figure 7(a) and Figure 7(b) show J-V characteristics of solar cells devices under illumination (AM $1.5 \mathrm{G}, 100 \mathrm{~mW} / \mathrm{cm}^{2}$ ) and under dark respectively. The solar cells devices performance, short circuit current density $\left(J_{s c}\right)$, open circuit voltage $\left(V_{o c}\right)$, fill factor $(F F)$, shunt resistance $\left(R_{s h}\right)$, series resistance $\left(R_{s}\right)$, and power conversion efficiency $(\eta)$ are shown in Table 1.

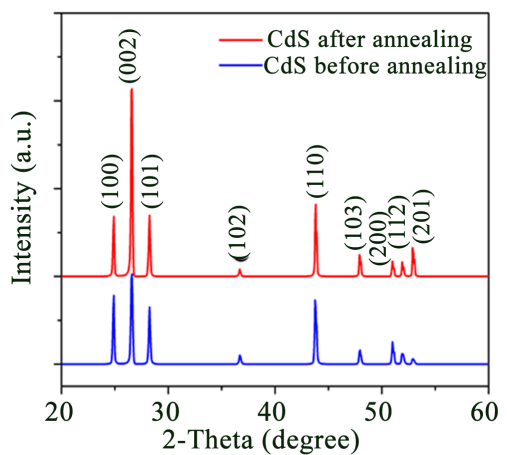

(a)

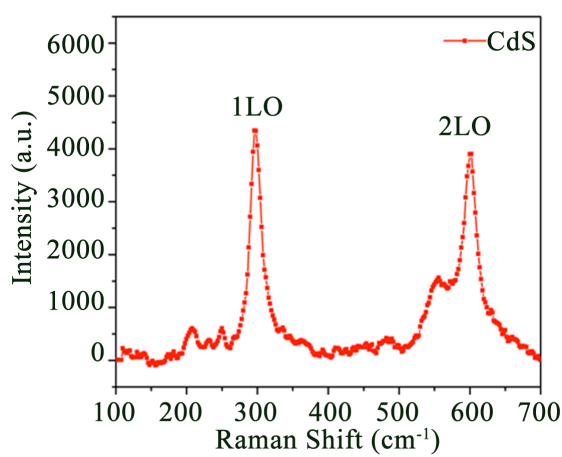

(b)

Figure 5. XRD patterns of CdS (a) Raman scattering spectroscopy of CdS (b).

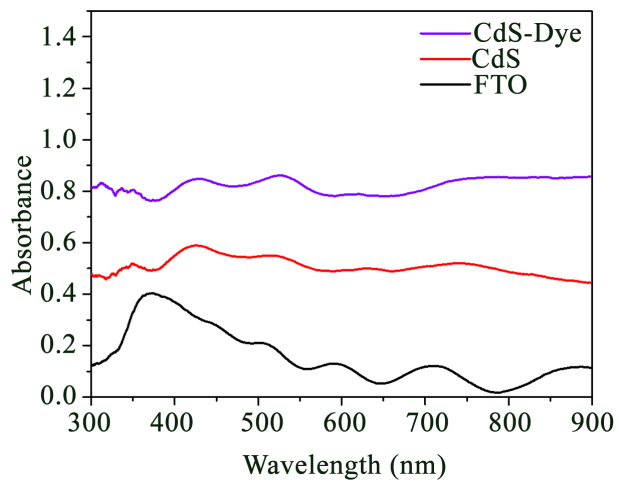

Figure 6. Absorption spectra of FTO, and CdS with and without dye.

Table 1. J-V Characterization of devices structures under illumination of AM 1.5.

\begin{tabular}{ccccccc}
\hline Devices & $J_{S C}\left(\mathrm{~mA} / \mathrm{cm}^{2}\right)$ & $V_{O C}(\mathrm{~V})$ & $F F(\%)$ & $R_{S h}\left(\Omega \cdot \mathrm{cm}^{2}\right)$ & $\boldsymbol{R}_{S}\left(\Omega \cdot \mathrm{cm}^{2}\right)$ & PCE (\%) \\
\hline CdS/MWNT-G & 1.02 & 0.21 & $26 \%$ & 20.04 & 9.14 & 0.056 \\
CdS/MWNT & 0.94 & 0.24 & $20 \%$ & 18.49 & 12.2 & 0.044 \\
CdS/G & 0.82 & 0.23 & $20 \%$ & 20.27 & 10.97 & 0.037 \\
\hline
\end{tabular}




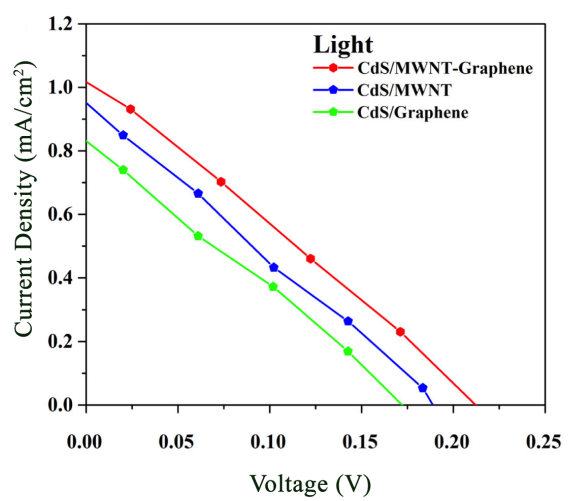

(a)

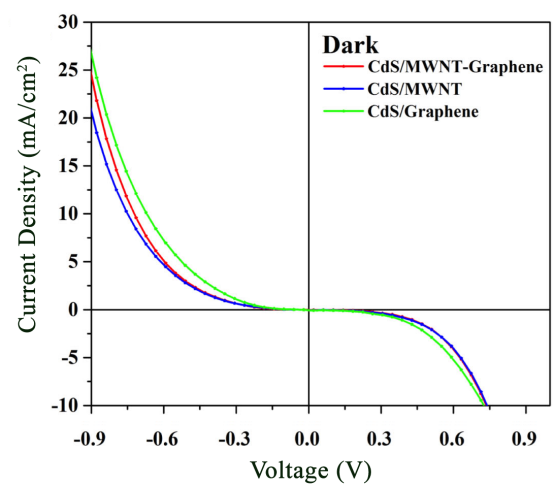

(b)

Figure 7. The J-V Characteristics of CdS/MWNT-G, CdS/MWNT, and CdS/G devices (a) under AM 1.5 G illumination and (b) in the dark.

The device CdS/MWNT-G displays the highest power conversion efficiency (0.056) and higher short circuit current density $\left(1.02 \mathrm{~mA} / \mathrm{cm}^{2}\right)$ when compared to the CdS/MWNT and CdS/G devices because the reduced recombination due to MWNT-G nanocomposites that effectively helped the diffusion of excited photoelectron from the dye molecules, which increase the charge injections and $J_{s c}$ as shown in Figure 4(g) and Figure 4(h). The fill factor improved from 20\% to $26 \%$ when the high conductive MWNT-G nanocomposite were used. High efficiency of CdS/MWNT-G also can be attributed to the lowest value of $R_{s}=9.14$ $\Omega \cdot \mathrm{cm}^{2}$ for the DSSCs device CdS/MWNT-G when compared with the others, and increasing $R_{s h}=20.04 \Omega \cdot \mathrm{cm}^{2}$ which in turn affect the DSSCs performance.

The DSSCs efficiency calculated from the equation [8] [12] [25]:

$$
\eta=\left(\frac{F F \cdot J_{s c} \cdot V_{o c}}{P_{i n}}\right) .
$$

\section{Conclusion}

MWNT, G, and MWNT-G nanocomposite film were successfully prepared by spray coating deposition on FTO, which employed as counter electrode to fabricate DSSCs with photo electrode $\mathrm{n}$-CdS. The properties of the thin film were analyzed and characterized by different techniques. An improvement in power conversion energy was observed when MWNT-G nanocomposite used in the photovoltaic device, which is attributed to large surface coverage of MWNT-G and increased the conductivity, while the lowest power conversion energy might be attributed to the poor dye regeneration.

\section{Acknowledgements}

Entidhar would like to thank the Department of Physics and Astronomy, University of Arkansas at Little Rock for its assistance. Thanks for Center for Integrative Nanotechnology Sciences at University of Arkansas at Little Rock for helping with SEM. 


\section{Conflicts of Interest}

The author declares no conflicts of interest regarding the publication of this paper.

\section{References}

[1] Chen, C., Zhai, Y., Li, C. and Li, F. (2014) Improving the Efficiency of Cadmium Sulfide-Sensitized Titanium Dioxide/Indium Tin Oxide Glass Photoelectrodes Using Silver Sulfide as an Energy Barrier Layer and a Light Absorber. Nanoscale Research Letters, 9, Article No. 605. https://doi.org/10.1186/1556-276X-9-605

[2] Li, G., Wu, L., Li, F., Xu, P., Zhang, D. and Li, H. (2013) Photoelectrocatalytic Degradation of Organic Pollutants via a CdS Quantum Dots Enhanced $\mathrm{TiO}_{2}$ Nanotube Array Electrode under Visible light Irradiation. Nanoscale, 5, 2118-2125. https://doi.org/10.1039/C3NR34253K

[3] Alkuam, E., Badradeen, E. and Guisbiers, G. (2018) Influence of CdS Morphology on the Efficiency of Dye-Sensitized Solar Cells. ACS Omega, 3, 13433-13441. https://doi.org/10.1021/acsomega.8b01631

[4] Su, J., Zhang, T., Li, Y., Chen, Y. and Liu, M. (2016) Photocatalytic Activities of Copper Doped Cadmium Sulfide Microspheres Prepared by a Facile Ultrasonic Spray-Pyrolysis Method. Molecules, 21, Article No. 735. https://doi.org/10.3390/molecules21060735

[5] Chen, Y., Feng, X., Liu, M., Su, J. and Shen, S. (2016) Towards Efficient Hydrogen Conversion: Fundamentals and Recent Progress in Based Chalcogenide Photocathodes. Nanophotonics, 5, 524-547. https://doi.org/10.1515/nanoph-2016-0027

[6] Sakimoto, K.K., Wong, A.B. and Yang, P. (2016) Self-Photosensitization of Nonphotosynthetic Bacteria for Solar-to-Chemical Production. Science, 351, 74-77. https://doi.org/10.1126/science.aad3317

[7] Chen, J., Yin, L., Fan, Z. and Chen, B. (2015) One-pot Synthesis of CdS Nanocrystals Hybridized with Single-Layer Transition-Metal Dichalcogenide Nanosheets for Efficient Photocatalytic Hydrogen Evolution. Angewandte Chemie International Edition, 54, 1210-1214. https://doi.org/10.1002/anie.201410172

[8] Alkuam, E., Mohammed, M. and Chen, T. (2017) Fabrication of CdS Nanorods and Nanoparticles with PANI for (DSSCs) Dye-Sensitized Solar Cells. Solar Energy, 150, 317-324. https://doi.org/10.1016/j.solener.2017.04.056

[9] Choi, J.Y., Kim, K.-J., Yoo, J.-B. and Kim, D. (1998) Properties of Cadmium Sulfide Thin Films Deposited by Chemical Bath Deposition with Ultrasonication. Solar Energy, 64, 41-47. https://doi.org/10.1016/S0038-092X(98)00047-4

[10] Tomita, Y., Kawai, T. and Hatanaka, Y. (1994) Properties of Sputter-Deposited CdS/CdTe Heterojunction Photodiode. Japanese Journal of Applied Physics, 33, 3383-3388. https://doi.org/10.1143/JJAP.33.3383

[11] Abdulelah, H., Ali, B., Mahdi, M.A., Abdullah, A.Q., Hassan, J.J. and Jennings, P. (2016) Fabrication and Characterization of Porous CdS/Dye Sensitized Solar Cells. Journal of Solar Energy, 2016, Article ID: 1093821. https://doi.org/10.1155/2016/1093821

[12] Alkuam, E., Mohammed, M. and Chen, T. (2017) Enhanced Synthesis of Cadmium Sulfide by Electrodeposition in Dye-Sensitized Solar Cells. Solar Energy, 157, 342-348. https://doi.org/10.1016/j.solener.2017.08.052

[13] Li, Y., Hu, Y., Peng, S., Lu, G. and Li, S. (2009) Synthesis of CdS Nanorods by an Ethylenediamine Assisted Hydrothermal Method for Photocatalytic Hydrogen 
Evolution. Journal of Physical Chemistry C, 113, 9352-9358. https://doi.org/10.1021/jp901505j

[14] Wang, Q., Xu, G. and Han, G. (2006) Synthesis and Characterization of Large-Scale Hierarchical Dendrites of Single-Crystal CdS. Crystal Growth \& Design, 6, 1776-1780. https://doi.org/10.1021/cg060017e

[15] Kim, D., Fahrenbruch, A.L., Lopez-Otero, A., Bube, R.H. and Jones, K.M. (1994) Measurement and Control of Ion-Doping-Induced Defects in Cadmium Telluride Films. Journal of Applied Physics, 75, 2673-2679. https://doi.org/10.1063/1.356220

[16] Pathan, H.M. and Lokhande, C.D. (2004) Deposition of Polycrystalline ZnO Thin Films by Successive Ionic Layer Adsorption and Reaction Process (SILAR). Inorganic Materials, 19, 610-616.

[17] Lanning, B.R. and Armstrong, J.H. (1992) Behavior of Solution Grown CdS for Thin-Film Solar Cell Technologies. International Journal of Solar Energy, 12, 247-255. https://doi.org/10.1080/01425919208909766

[18] Alkuam, E. (2019) An Effective of Dye Molecules with Cadmium Sulfide Nanorods in Dye Sensitized Solar Cell (DSSCs). Advances in Materials Physics and Chemistry, 9, 37-47. https://doi.org/10.4236/ampc.2019.94004

[19] Zhang, D.W., Chen, S., Li, X.D., Wang, Z.A., Shi, J.H., Sun, Z., Yin, X.J. and Huang, S.M. (2009) Cadmium Sulfide Quantum Dots Grown by Chemical Bath Deposition for Sensitized Solar Cell Applications. Photonics and Optoelectronics Meetings (POEM) 2009: Solar Cells, Solid State Lighting, and Information Display Technologies. International Society for Optics and Photonics, Vol. 7518, Article ID: 751804. https://doi.org/10.1117/12.840612

[20] Berry, A.K., Amirtharaj, P.M., Du, J., Boone, J.L. and Martin, D.D. (1992) Photoluminescence and Raman Studies of CdS Films Grown by Metal-Organic Chemical Vapor Deposition on Si\{111\} Substrates. Thin Solid Films, 219, 153-156. https://doi.org/10.1016/0040-6090(92)90736-U

[21] Marinho, B., Ghislandi, M., Tkalya, E., Koning, C.E. and De With, G. (2012) Electrical Conductivity of Compacts of Graphene, Multi-Wall Carbon Nanotubes, Carbon black, and Graphite Powder. Powder Technology, 221, 351-358. https://doi.org/10.1016/j.powtec.2012.01.024

[22] Abdulalmohsin, S., Li, Z., Mohammed, M., Wu, K. and Cui, J. (2012) Electrodeposited Polyaniline/Multi-Walled Carbon Nanotube Composites for Solar Cell Applications. Synthetic Metals, 162, 931-935. https://doi.org/10.1016/j.synthmet.2012.04.001

[23] Hossain, M.F. and Takahashi, T. (2012) Comparative Study of CdS-Sensitized and Conventional Dye-Sensitized Solar Cells. 20127 th International Conference on Electrical and Computer Engineering, Dhaka, 20-22 December 2012, 209-212. https://doi.org/10.1109/ICECE.2012.6471522

[24] Chuu, D.S., Dai, C.M., Hsieh, W.F. and Tsai, C.T. (1991) Raman Investigations of the Surface Modes of the Crystallites in CdS Thin Films Grown by Pulsed Laser and Thermal Evaporation. Journal of Applied Physics, 69, 8402-8404. https://doi.org/10.1063/1.347405

[25] Eshaghi, A. and Aghaei, A.A.I.L. (2015) Effect of $\mathrm{TiO}_{2}-\mathrm{Graphene}$ Nanocomposite Photoanode on Dye-Sensitized Solar Cell Performance. Bulletin of Materials Science, 38, 1177-1182. https://doi.org/10.1007/s12034-015-0998-5 